\title{
AVALIACÃO DA TEMPERATURA DE BALCÕES REFRIGERADOS DE SUPERMERCADOS DE PALMAS - TO
}

Temperature assessment of refrigerated counters of supermarkets of Palmas - TO



Evaluación de temperatura de mostradores refrigerados de supermercados de Palmas $-T O$

Amanda Mellissa Bezerra Oliveira ${ }^{* 1}$, Dhayna Oliveira Sobral ${ }^{1}$, Karolline Ribeiro Lima Beckmam ${ }^{1}$, Letícia Vieira Emiliano Camargo ${ }^{1}$, Nayra Pontes Madalena ${ }^{1}$, Abraham Damian Giraldo Zuniga² .

${ }^{1}$ Aluna bolsista do grupo PET Engenharia de Alimentos, Engenharia de Alimentos, Universidade Federal do Tocantins, Palmas - TO, Brasil.

${ }^{2}$ Tutor do grupo PET Engenharia de Alimentos, Engenharia de Alimentos, Universidade Federal do Tocantins, Palmas - TO, Brasil.

*Correspondência: PET Engenharia de Alimentos, Universidade Federal do Tocantins, Av. NS 15, 109 Norte,

Palmas, Tocantins, Brasil.CEP:77.010-090.e-mail pet_engal@uft.edu.br.

Artigo recebido em 29/04/2019 aprovado em 03/05/2019 publicado em 16/06/2019.

\section{RESUMO}

Os balcões refrigerados utilizados para expor o produto final ao consumidor, muitas vezes não atendem aos parâmetros de temperatura para o armazenamento adequado de produtos perecíveis. O presente trabalho teve como objetivo avaliar a temperatura de refrigeração de balcões de armazenamento de produtos perecíveis em três supermercados do município de Palmas-To. Para tanto aferiu-se, com o auxílio de um termômetro digital infravermelho, a temperatura dos balcões refrigerados dos supermercados, identificados genericamente como A, B e C. Foram detectadas irregularidades em todos os supermercados avaliados, o que representa um grave risco ao consumidor. Dessa forma, os estabelecimentos devem tomar medidas para que os alimentos sejam armazenados adequadamente e os órgãos de fiscalização devem intensificar a vigilância da temperatura de refrigeração dos balcões. Palavras-chave: Alimentos perecíveis; Balcões refrigerados; Temperatura de refrigeração.

\section{ABSTRACT}

The refrigerated counters used to expose the final product to the consumer often do not meet the temperature parameters for the adequate storage of perishable products. The present work had as objective to evaluate the refrigeration temperature of storage counters for perishable products in three supermarkets of the municipality of Palmas-To. For this purpose, the temperature of the refrigerated counters of the supermarkets, generically identified as $A, B$ and $C$, was measured using an infrared digital thermometer. Irregularities were detected in all the supermarkets evaluated, which represents a serious risk to the consumer. Accordingly, establishments must take action to ensure that food is properly stored, and surveillance entities must intensify oversight of the counters' refrigeration temperature.

Keywords: Perishable food; Refrigerated counters; Cooling temperature.

\section{RESUMEN}

Los mostradores refrigerados utilizados para exponer el producto final al consumidor em muchos de los casos no mantienen la temperatura ideal para el almacenamiento adecuado de alimentos perecibles. El objetivo de este trabajo fue evaluar la temperatura de refrigeración de los almacenes refrigerados de productos perecibles en tres supermercados de la ciudad de palmas, estado do Tocantins. Para cumplir este objetivo y con la ayuda de un termómetro digital infrarrojo fueron medidas las temperaturas de los mostradores refrigerados de los 
supermercados, identificados genéricamente como $A, B$ y $C$, se detectaron irregularidades en todos los supermercados evaluados, lo que representa un grave riesgo para el consumidor. De esta manera, los establecimientos deben tomar medidas para almacenar adecuadamente los alimentos y los órganos de control deben intensificar el control de la temperatura de refrigeración de los mostradores refrigerados.

Palavras claves: Alimentos perecibles; mostradores refrigerados; Temperatura de refriferación.

\section{INTRODUÇÃO}

A preservação dos alimentos pela conservação a frio, seja refrigeração ou congelamento, tem como processo fundamental a utilização de baixa temperatura. Conforme consta no Glossário da Vigilância Sanitária, a cadeia do frio diz respeito ao resfriamento e manutenção dessa temperatura desde o processo de produção do produto até o consumo final. Trata-se de uma série de procedimentos que objetiva a preservação da qualidade do produto perecível durante todo o processamento e armazenamento sob diferentes aspectos, como a manutenção das características sensoriais, nutricionais, organolépticas e higiênicas (EMBRAPA 2017; BRASIL, 2011; SANTOS, 2014; SOUZA et al, 2013).

O manejo correto do binômio tempo e temperatura possui grande importância para a qualidade do processo de produção e armazenagem dos alimentos. Diversos produtos comercializados em supermercados são perecíveis, exigindo cuidados especiais no que diz respeito à temperatura de transporte, armazenamento e exposição. Os alimentos perecíveis são expostos em balcões refrigerados que permitem praticidade ao consumidor na escolha entre as opções oferecidas de produtos. Em geral, os balcões refrigerados utilizados para expor o produto final ao consumidor, muitas vezes não atendem aos parâmetros de temperatura para o armazenamento adequado de produtos perecíveis (SILVA et al., 2005; ABRAS, 2001; FONSECA, 2006).

O leite, a carne e seus derivados são produtos sujeitos a diversas alterações durante a manipulação, distribuição e comercialização no varejo. As temperaturas e cargas das gôndolas de supermercados devem ser cuidadosamente observadas, pois alguns graus a mais causam comprometimento da chamada vida-de-prateleira dos produtos (MACÊDO et al., 2000; MENDES et al., 2001).

De acordo com o artigo 31, para produtos resfriados, da Norma Regulamentadora $n^{\circ}$ 4/2014 DIVISA/SVS/SES as temperaturas de armazenamento de carnes bovina e suína, aves, entre outras, e seus produtos manipulados crus devem ser mantidos até $4^{\circ} \mathrm{C}$ (quatro graus Celsius) e validade de até três dias; Leite e derivados até $7^{\circ} \mathrm{C}$ (sete graus Celsius) e validade de cinco dias (BRASIL, 2014).

A cadeia do frio além de manter o produto, prolonga o seu período de comercialização; mas se faz necessário a verificação do seu uso, quanto à temperatura ideal de conservação para cada tipo de alimento, conforme o artigo 36 da Norma Regulamentadora $n^{\circ}$ 4/2014 - DIVISA/SVS/SES, uma vez que é possível que os estabelecimentos desliguem os congeladores e refrigeradores durante a noite para poupar energia, religando-os na manhã seguinte, tornando a refrigeração deficiente nos pontos do comércio varejista (NUVOLARI, 2017).

Diante disso, o presente trabalho teve como objetivo avaliar a temperatura de refrigeração de balcões de armazenamento de produtos perecíveis em três supermercados do município de Palmas - TO.

\section{MATERIAIS E MÉTODOS}

Foram selecionados três supermercados na cidade de Palmas, no estado do Tocantins, Brasil. Os estabelecimentos foram escolhidos de maneira que estivessem distribuídos nas três grandes regiões da cidade. Os supermercados foram identificados genericamente como A, B e C, estando o supermercado A localizado na região Sul, o supermercado B na região 
Central e o supermercado $\mathrm{C}$ na região Norte.

Nos três supermercados, foram aferidas as temperaturas de todos os balcões que continham produtos cárneos e produtos lácteos refrigerados com o auxílio de um termômetro digital infravermelho SMART SENSOR AR320 $\left(-32^{\circ} \mathrm{C} \sim 380^{\circ} \mathrm{C}\right)$.

As temperaturas foram medidas durante três dias aleatórios durante a semana, em dois horários nesses dias, a primeira medição às sete horas da manhã e a segunda ao meio dia. Em cada balcão a temperatura foi medida em três pontos distintos para fazer uma média das três temperaturas.

\section{RESULTADOS E DISCUSSÃO}

O controle de temperatura é essencial para garantir um produto que atenda ao padrão de qualidade exigido (BAASCH et al, 2009). Segundo a Norma Regulamentadora $n^{\circ}$ 4/2014 - DIVISA/SVS/SES, a faixa de temperatura ideal para produtos refrigerados varia de 0 a $10^{\circ} \mathrm{C}$, de acordo com o produto. Para carnes bovinas, suínas, de aves, além de outras, a temperatura de armazenamento não pode ultrapassar $4^{\circ} \mathrm{C}$. Para alimentos derivados de leite, a temperatura máxima de armazenamento é de $7^{\circ} \mathrm{C}$ (BRASIL, 2014).

Os valores de temperatura dos balcões refrigerados, obtidos nos supermercados A, B e C, podem ser verificadas nas Tabelas 1, 2 e 3 .

No Supermercado A, foram obtidos valores de temperaturas para quatro produtos (carne resfriada em pedaços, queijos regionais, queijos importados, além de carne moída resfriada), vide Tabela 1.

Tabela 1. Temperaturas dos balcões do Supermercado A.

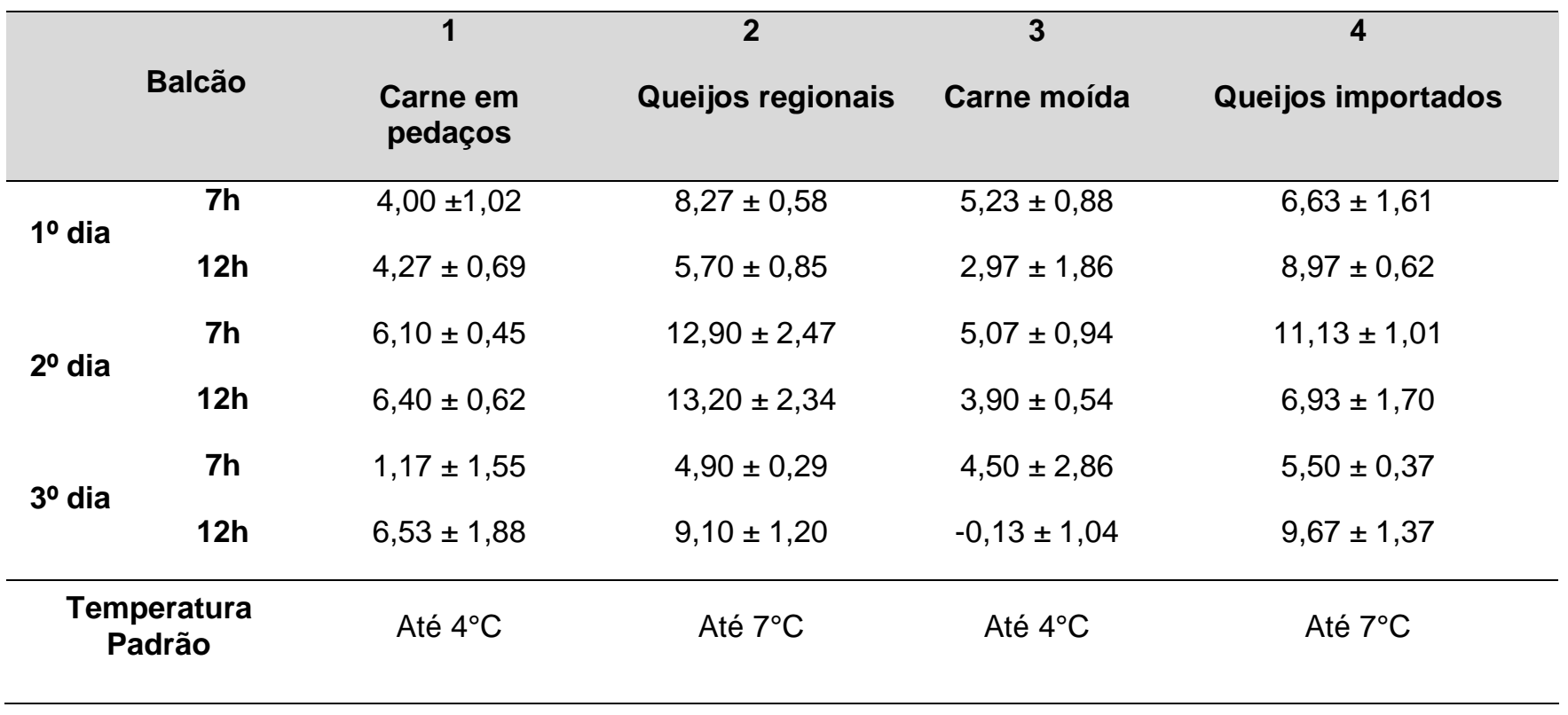

Em relação ao balcão contendo carne em pedaços, o Supermercado A obteve médias de temperaturas variando entre $1,17^{\circ} \mathrm{C}$ e $6,53^{\circ} \mathrm{C}$, onde as menores temperaturas foram registradas no horário de 7h. No geral, apenas dois do seis valores medidos se encontravam dentro da temperatura estabelecida pela
Legislação $\left(4^{\circ} \mathrm{C}\right)$, representando $33,3 \%$ do total, enquanto os outros $66,7 \%$ estavam fora do padrão.

Dentre os valores obtidos para os queijos regionais, observou-se que apenas $33,3 \%$ se mostrou satisfatório. Os dados coletados apresentaram variação entre $4,9^{\circ} \mathrm{C}$ e $13,2^{\circ} \mathrm{C}$, onde, $66,7 \%$ dos valores se encontravam acima da temperatura ideal de 
acondicionamento $\left(7^{\circ} \mathrm{C}\right)$. Já a análise do balcão de queijos importados mostrou que 50\% das médias se enquadravam dentro do padrão, enquanto os outros $50 \%$ se mostraram superior ao limite estabelecido pela Lei.

Quanto aos dados de armazenamento da carne moída, percebeu-se que apenas 33,3\% dos valores se encontravam em conformidade com o padrão de temperatura $\left(4^{\circ} \mathrm{C}\right)$, enquanto $50 \%$ se mantinham acima do valor e $16,6 \%$ se encontravam abaixo do valor exigido.

Tabela 2. Temperaturas dos balcões do Supermercado B.

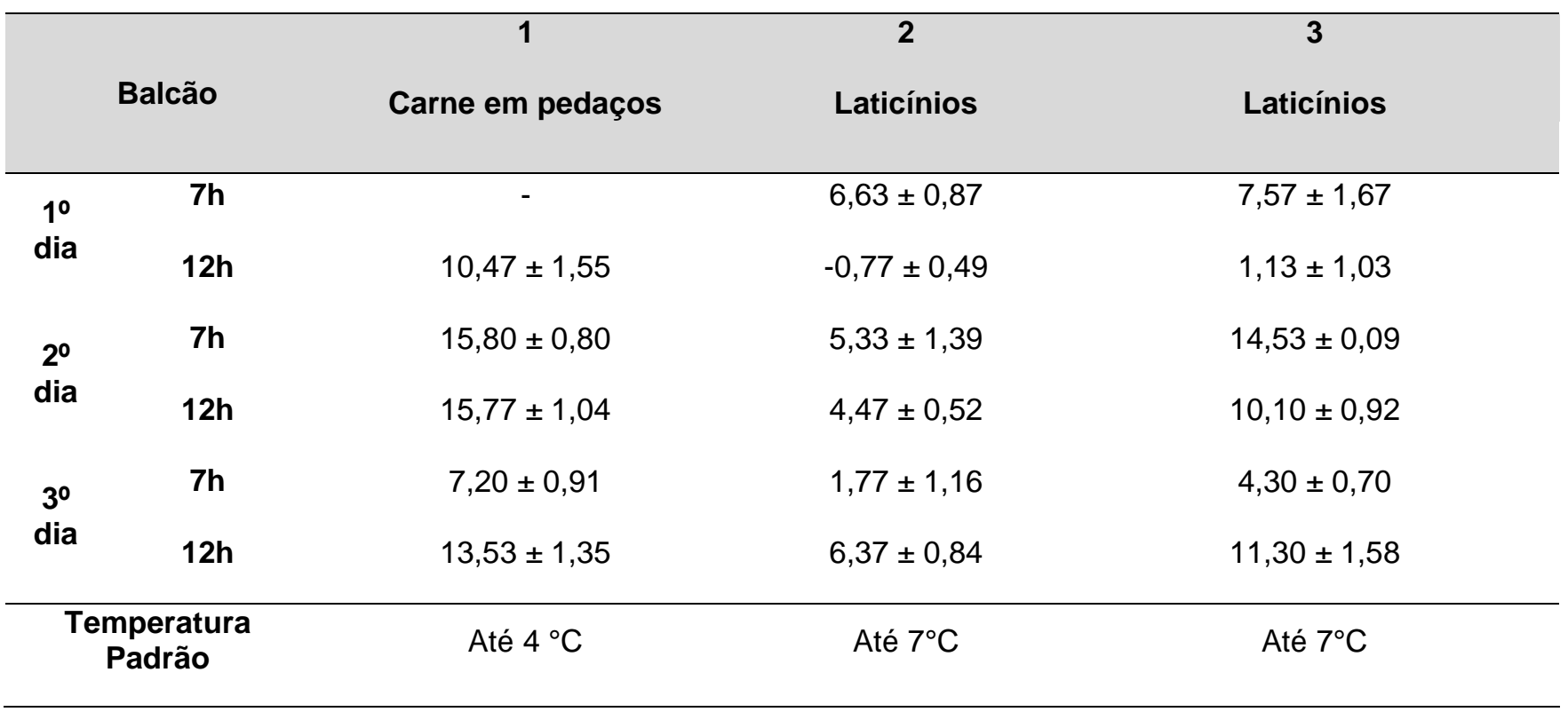

No Supermercado B, foram coletados dados de temperaturas de três pontos diferentes (carne resfriada em pedaços e dois pontos contendo laticínios diversos).

No primeiro dia, não foi possível realizar a coleta de temperaturas da carne em pedaços na parte da manhã, devido à limpeza e manutenção das gôndolas de refrigeração do supermercado, assim como mostra a Tabela 2. Nos demais dias e horários, verificou-se que todas as temperaturas de armazenamento eram superiores à máxima recomendada para esse tipo de produto $\left(4^{\circ} \mathrm{C}\right)$, representando $100 \%$ de inadequação.
Quanto ao balcão 2, contendo laticínios, verificou-se que $83,3 \%$ dos valores se mostraram adequados para consumo, obedecendo o padrão ideal de armazenamento $\left(7^{\circ} \mathrm{C}\right)$, enquanto apenas $16,6 \%$ se mostraram inadequados, com temperatura abaixo do recomendado.

No balcão 3, por sua vez, os valores de temperatura aferidos para laticínios mostraram que apenas 33,3\% das temperaturas se enquadravam na faixa ideal, enquanto os outros $66,7 \%$ estavam acima do valor máximo recomendado. 
Tabela 3. Temperaturas dos balcões do Supermercado C.

\begin{tabular}{|c|c|c|c|c|}
\hline & Balcão & $\begin{array}{c}1 \\
\text { logurtes }\end{array}$ & $\begin{array}{c}2 \\
\text { Manteiga/margarina }\end{array}$ & $\begin{array}{c}3 \\
\text { Presuntos/queijos }\end{array}$ \\
\hline \multirow{2}{*}{$\begin{array}{c}1^{\circ} \\
\text { dia }\end{array}$} & $7 \mathrm{~h}$ & $6,30 \pm 0,70$ & $3,67 \pm 1,11$ & $5,23 \pm 0,17$ \\
\hline & $12 \mathrm{~h}$ & $-1,27 \pm 0,54$ & $-4,63 \pm 1,18$ & $-3,13 \pm 0,76$ \\
\hline \multirow{2}{*}{$\begin{array}{c}20 \\
\text { dia }\end{array}$} & $7 \mathrm{~h}$ & $6,20 \pm 0,33$ & $3,77 \pm 0,65$ & $5,40 \pm 0,16$ \\
\hline & $12 \mathrm{~h}$ & $2,10 \pm 0,73$ & $4,80 \pm 0,65$ & $9,20 \pm 1,85$ \\
\hline \multirow{2}{*}{$\begin{array}{c}30 \\
\text { dia }\end{array}$} & $7 \mathrm{~h}$ & $8,70 \pm 0,22$ & $6,30 \pm 0,54$ & $6,40 \pm 1,71$ \\
\hline & $12 \mathrm{~h}$ & $0,30 \pm 1,02$ & $5,10 \pm 1,02$ & $7,73 \pm 1,11$ \\
\hline \multicolumn{2}{|c|}{$\begin{array}{c}\text { Temperatura } \\
\text { Padrão }\end{array}$} & Até $7^{\circ} \mathrm{C}$ & Até $7^{\circ} \mathrm{C}$ & Até $4^{\circ} \mathrm{C}$ \\
\hline
\end{tabular}

Como o Supermercado C não possui balcão de carne refrigerada, foram coletados valores de temperatura apenas para laticínios e presuntos, vide Tabela 3. Dentre os dados obtidos para iogurtes, observou-se que $66,7 \%$ dos valores estavam em conformidade com o padrão exigido, enquanto $16,6 \%$ estavam abaixo da temperatura ideal, apresentando temperatura de $-1,27^{\circ} \mathrm{C}$ e $16,6 \%$ estavam acima do valor máximo recomendado, com valor de $8,7^{\circ} \mathrm{C}$.

Para o ponto de coleta contendo laticínios (manteiga e margarina), os valores obtidos mostraram que $83,3 \%$ se encontravam em acondicionamento adequado, com temperaturas variando entre $3,6^{\circ} \mathrm{C}$ e $6,3^{\circ} \mathrm{C}$, enquanto apenas $16,6 \%$ foram considerados inadequados por estar abaixo do valor exigido, com temperatura de $-4,6^{\circ} \mathrm{C}$.

O terceiro balcão analisado, continha queijos e presuntos. A faixa de temperatura obtida variou entre $3,1^{\circ} \mathrm{C}$ e $9,2^{\circ} \mathrm{C}$. Em relação aos queijos, verificou-se que $50 \%$ dos valores se encontravam dentro do padrão. Para os presuntos, observou-se que $100 \%$ dos valores eram inadequados, uma vez que a temperatura máxima de armazenamento para frios e embutidos $\left(4^{\circ} \mathrm{C}\right)$ é diferente da temperatura máxima de laticínios $\left(7^{\circ} \mathrm{C}\right)$.

É importante ressaltar que o controle da temperatura pode prevenir, reduzir ou eliminar os riscos de contaminação de origem microbiana. A temperatura do balcão de armazenamento é de fundamental importância, uma vez que o aumento da temperatura influencia diretamente no aumento da velocidade das reações bioquímicas e biológicas nos alimentos (SOUSA et al, 2003).

Um estudo realizado por COSTA et al (2012) verificou que entre as temperaturas no balcão de carnes refrigeradas, apenas $38,09 \%$ dos produtos se encontravam entre $0^{\circ} \mathrm{C}$ e $7^{\circ} \mathrm{C}$, e em $61,91 \%$, a temperatura estava entre $10^{\circ} \mathrm{C}$ e $18^{\circ} \mathrm{C}$. Também foi possível observar que em $100 \%$ dos estabelecimentos, os balcões de refrigeração não possuíam termômetro e planilha de controle de temperatura. Outro fator a ser considerado é a capacidade de armazenamento do balcão ou câmara fria, uma vez que o excesso de produtos acondicionados pode causar maior deterioração de produtos perecíveis. 
ROCHA et al. (2014), em estudo semelhante no município de Palmas, porém utilizando, para a aferição da temperatura, um termômetro do tipo espeto, verificaram que os alimentos não estavam sendo refrigerados/congelados de acordo com a Norma Regulamentadora $n^{\circ} 4 / 2014$, prejudicando assim o consumidor, já que este estaria comprando produtos impróprios. Isso pode ser atribuído à falta de capacitação em BPF dos responsáveis pelas empresas e também o não acompanhamento dessas empresas por parte do órgão responsável.

STOLTE e TONDO (2001) afirmaram que manutenção das gôndolas de refrigeração fechadas durante a maior parte do tempo contribui de decisivamente para a adequação dos produtos. Enquanto os balcões refrigerados tipo autosserviço se mostram mais propícios à troca de calor com o ambiente. Dessa forma, surge a necessidade de adicionar barreiras nesses equipamentos como, por exemplo, cortina de ar, com o intuito de reduzir as trocas de calor entre o equipamento e o ambiente.

Em equipamentos de grande porte, como gôndolas e balcões refrigerados, a temperatura pode variar de acordo com o local e não ser a mesma em todos os pontos dentro da área refrigerada, assim, é importante conhecer as temperaturas em cada ponto de refrigeração para garantir que todos os alimentos estejam adequadamente armazenados. É comum que ocorram falhas em equipamentos ou até mesmo, falha humana durante manuseio dos equipamentos. Portas de balcões e câmaras frias deixadas abertas por clientes ou funcionários, tomadas desligadas acidentalmente ou com o intuito de economizar energia durante a noite, são exemplos de problemas do cotidiano. Caso essas condições se mantenham por longos períodos, pode haver perda de estoque, acarretando prejuízos ao lojista, além de risco de saúde ao consumidor (ZOTARELLI, 2016).

\section{CONCLUSÃO}

Todos os supermercados apresentaram irregularidades em relação à temperatura de refrigeração de balcões de armazenamento de produtos perecíveis, o que representa um grave risco ao consumidor. Dessa forma, os estabelecimentos devem tomar medidas para que os alimentos sejam armazenados adequadamente e os órgãos de fiscalização devem intensificar a vigilância, garantindo maior segurança ao consumidor.

\section{AGRADECIMENTOS}

Este trabalho foi desenvolvido pelo Programa de Educação Tutorial (PET) Engenharia de Alimentos, com o apoio da Universidade Federal do Tocantins (UFT).

Todos os autores declararam não haver qualquer potencial conflito de interesses referente a este artigo.

\section{REFERÊNCIAS}

ABRAS. Associação brasileira de supermercados. Disponível em: Acesso em 13/06/2018.

BAASCH, C. A.; HASSE, C. R.; ALEXANDRINI, F. Monitoração do controle de temperaturas de frigorífico conforme circular 175 do mapa. SEGeT - Simpósio de Excelência em Gestão e Tecnologia. 2009.

BRASIL. Norma Regulamentadora $\mathrm{n}^{\circ}$ 4/2014 DIVISA/SVS/SES. Disponível em: https://www.legisw eb.com.br/legislacao/?id=281122. Acesso em: 08/09/20 18.

BRASIL. Secretaria de Estado de Saúde de Mato Grosso do Sul, Glossário da Vigilância Sanitária. Disponível em: http://www.saude.ms.gov.br/. Acesso em: 07/09/2018.

COSTA, J. P. N.; SANTOS, V. V. M.; SILVA, G. R.; MOURA , F. M. L.; SIQUEIRA , M. G. F. M.; GURGEL, C. A. B.; MOURA, A. P. B. L. Condições de armazenamento e acondicionamento de carnes in natura comercializadas em minimercados. Medicina Veterinária, Recife, v.6, n.4, p.10-15, 2012.

EMBRAPA - Empresa Brasileira de Pesquisa Agropecuária. 2017. Disponível em: https://www.embrapa.br/. Acesso em: 08/08/2018. 
FONSECA, K. L. Avaliação da cadeia de frios em um supermercado no Distrito Federal. Trabalho de Conclusão de Curso apresentado a UCB. Brasília, 2006. Disponível em: http://qualittas.com.br/uploads/d ocumentos/Avaliacao $\% 20 \mathrm{da} \% 20$ Cadeia $\% 20 \mathrm{de} \% 20 \mathrm{Frei}$ os $\% 20 \mathrm{em} \% 20$ umSupermercado $\% 20$ no $\% 20$ Distrito $\% 2$ 0Federal\%20\%20Karina\%20Lettieri\%20Fonseca.PDF. Acesso em: 08/09/2018.

MACÊDO, J. A. B. de; AMORIM, J. M.; LIMA, D. C.; SILVA, P. M.; VAZ, U. P. Avaliação da temperatura de refrigeração nas gôndolas de exposição de derivados lácteos em supermercados da região de Juiz de Fora/MG. Revista Leite e Derivados, n. 53, p.20-30, 2000 .

MENDES, A.C.R.; SANTANA NETA, L.G.; COSTA, D.S.; ALMEIDA, J.F. Condições de comercialização de cortes cárneos em supermercados da cidade de Salvador, BA. Aspectos higiênico-sanitários e de conservação. Revista Higiene Alimentar, v.15, n.83, p.58-62, 2001.

NUVOLARI, C. M. BOAS PRÁTICAS DE FABRICAÇÃO E A CADEIA DO FRIO NOS SUPERMERCADOS DE BOTUCATU - SP. $84 \mathrm{f}$. Dissertação (Mestrado) - Curso de Ciências Agronômicas, UNESP, Botucatu-SP, 2017.

ROCHA, P. R. A.; ROCHA, E. F.; ALVES, M. R. R.; FREITAS, I. R. Conservação de produtos refrigerados e congelados expostos para a venda em supermercados da cidade de Palmas-TO. Journal of Bioenergy and Food Science, Macapá, v.1, n. 2, p. 27-31, jul. / set. 2014.
SANTOS, G. - Instalações frigoríficas. Lisboa: ISEL, 2014.

SILVA JR. E. A. Manual de Controle HigiênicoSanitário em Serviço de Alimentação. São Paulo: varela, 2005, 397p.

SOUSA, C. L.; PUERARI, F. C.; NEVES, E. C. A. Avaliação da Temperatura de Balcões e Câmaras Frias de Armazenamento de Queijos e Embutidos em Supermercados da Cidade de Belém - PA (Brasil). Boletim do Centro de Pesquisa de Processamento de Alimentos, v. 21, n. 1, 2003.

SOUZA, M. C.; TEIXEIRA, L. J. Q.; ROCHA, C. T. da; FERREIRA, G. A. M.; FILHO, T. L. Emprego do frio na conservação de alimentos. Enciclopédia Biosfera, Centro Científico Conhecer, Goiânia, v.9, N.16; p.1035. 2013. Disponível em: http://www.conhecer .org.br/enciclop/2013a/agrarias/EMPREGO\%20DO\%2 0FRIO.pdf. Acesso em: 12/06/2018.

STOLTE, D.; TONDO, E. C. Análise de perigos e pontos críticos de controle em uma unidade de alimentação e nutrição. Revista Higiene Alimentar, v. 15, n. 85, p.41-49, 2001.

ZOTARELLI, M. Temperatura de armazenamento de produtos congelados: Qual é a ideal para seu estoque? Tecnologia para o varejo. 2016. Disponível em: https://nexxto.com/temperatura-de-armazenamento-decongelados/ Acesso em: 08/09/2018. 